\title{
Rent-to-own agreements: Customer characteristics and contract outcomes
}

\author{
Michael H. Anderson Sanjiv Jaggia
}

\begin{abstract}
The rent-to-own (RTO) industry, by offering immediate access to household goods for a small periodic fee with no credit check or down payment, has strong appeal to low income and financially distressed consumers. An important policy question is whether an RTO agreement is used as a rental/lease with build-in purchase option or as something more akin to an installment loan. Given the embedded options to return the item or to purchase it early, the actual rent paid by RTO customers is substantially lower than the oft-reported total rent which assumes that agreements go to term. We employ a log-normal censored regression model to analyze the influence of customer demographics as well as the transactional details of the contract on the rent paid by consumers using rent-to-own. Our main conclusions are (1) it is the "working poor" that are likely to pay more rent, (2) there appears to be a clientele effect with customers paying more rent under bi-weekly and monthly, as opposed to weekly, payment schedules, and (3) customers who exhibit delinquency in making contractual payments generally end up paying more rent. Further, our data allows some observations on annual percentage rates by illustrating the business risk present for RTO stores as well as the cross-subsidization of consumers.
\end{abstract}

JEL classification: C24; D14; G29

Keywords: Transactions data; Censored data; Tobit model; Log-normal distribution; Consumer credit; Payment schedule

\section{Introduction}

This paper represents a comprehensive study of the nature of rent-to-own (RTO) contracts. We provide new insights into the nature of this financial contract by applying careful econometric 
analysis to actual detailed transactional data drawn from stores in the industry. While the extant literature has relied on relatively small scale customer interviews or surveys, ${ }^{1}$ the richness of our data allows quantification of variables otherwise unavailable. Two general themes emerge from our analysis with parametric models for censored data. The first is a demographic picture of RTO customers. As one might expect, the typical RTO customer can be described as a member of the "working poor," and we show how variations in demographic characteristics impact the amount of rent that a customer pays. These results are consistent with and complementary to the existing literature. The second, and more interesting, theme of our analysis relates to actual transactional details of the contracts. For instance, we are able to examine the impact of payment frequency and late payment history. We find that more rent is paid by customers who use bi-weekly and monthly, rather than weekly, payment schedules as well as, surprisingly, those who are delinquent in making payments. In addition to the various implications that emerge from the formal model, useful descriptive statistics are also provided which, interesting in and of themselves, contribute to our understanding of the nature of rent-to-own.

The rent-to-own industry from its beginnings in the 1960s has grown into an important sector of the retailing industry. Currently, there are over 8000 RTO stores in the United States with revenues of over US\$ 5.3 billion (APRO, 2001). The heart of the RTO arrangement is that consumers gain immediate access to new or used merchandise - most commonly appliances, electronics or furniture - with neither a credit check nor down payment in exchange for a rental payment due either weekly, bi-weekly or monthly. The agreement has a fixed time period, usually from 12 to 24 months; however, the consumer may terminate the contract at any point by returning the merchandise or by using a lump sum payment option. Should all payments be made, or the early purchase option used, the customer takes ownership of the merchandise. However, no adverse credit action occurs if the consumer decides to terminate after only one payment or after just a few.

The industry serves to a large extent lower income consumers. As such, RTO transactions are often grouped with other alternative financial services such as check-cashing stores, payday lenders and pawn shops (for an overview see Swagler, Burton, \& Lewis, 1995). These transactions have produced much interest among consumer advocates who argue that they may take advantage of low income consumers who can least afford to pay high prices. ${ }^{2}$ The extreme form of this argument is that RTO agreements are really disguised installment agreements at usurious interest rates aimed to exploit unsophisticated consumers with few alternatives. ${ }^{3}$ In contrast, Anderson and Jackson (2001) argue that the contract contains many option-like features which are valuable for such consumers. A key element in this debate is the amount of rent a consumer actually pays and it is this open empirical question that our paper seeks to address.

The issue is an important public policy question, and one which has generated a fair amount of attention from government. At the state level, 47 states have passed laws regulating RTO transactions and federal legislation has been proposed. ${ }^{4}$ Further, the Federal Trade Commission has produced a major report on the industry (FTC, 2000).

\footnotetext{
${ }^{1}$ FTC (2000) is an exception as it surveys 524 customers identified from a sample of 12,000 consumers.

${ }^{2}$ See Andreasen (1993) for an introduction to the issues of consumer advocacy for the disadvantaged.

${ }^{3}$ Freedman (1993) notes the high annual percentage interest rates and Walden (1990) argues that RTO prices substantially exceed dealer cost while Hill, Ramp, and Silver (1998) argue that prices cannot be justified by the return option or other services offered. McKernan, Lacko, and Hastak (2003), Swagler and Wheeler (1989), and Zikmund-Fisher and Parker (1999) examine consumer experience and motivation for entering into a RTO agreement.

${ }^{4}$ North Carolina, New Jersey and Wisconsin are the three exceptions. Lacko, McKernan, and Hastak (2002) and their citations provide a very good regulatory overview.
} 
This study examines the rent to own arrangement using a unique data set of transactional information drawn from four RTO stores in the Southeast. We take as the dependent variable the proportion of rent paid relative to the amount due if the contract went full term. This variable is important for two reasons. First, as a measure of financial obligation, it contributes insight into customer usage. Second, for purchases, it speaks to the actual cost of this financing arrangement. It also enables the development of novel stylized facts contributing to our understanding of these consumers and to the associated policy debate. We have information on personal characteristics of customers (e.g., gender, age and income level). Also, we have transaction-specific information-divided into contract structure (e.g., required payment frequency and total amount due), contract usage (e.g., if it is a repeat customer and, if so, the number of prior transactions), and contract payment history (e.g., proportion and variability of late payments). We assess the influence of such determinants on the proportion of rent paid. As the data represent a complete transaction history up to the data acquisition date, a significant percent of the observations are censored, i.e., active contracts with customers continuing to make payments. In order to deal appropriately with such censoring, we estimate a standard Tobit-type normal model as well as a more appropriate lognormal model.

The paper is organized in the following way. The next section describes the data set and the variables used in the model. Section 3 contains the methodology and the specification issues. Section 4 discusses the empirical results, identifying several empirical regularities. Section 5 concludes.

\section{Data and variables}

The data set was drawn from proprietary information from four stores of a small rent-to-own (RTO) chain in the Southeast. The stores were located in three states: Alabama, Louisiana and two in Mississippi. It represents all available transactional records as of the date gathered and was filtered only to remove personal information to ensure consumer confidentiality. The information was gathered with the cooperation of the Association of Progressive Rental Organizations (APRO), the industry trade group; High Touch, Inc., the primary supplier of RTO store management software; and the anonymous chain owner. At the store level, the detailed history of an individual transaction - from which we draw our data - is automatically purged 14 months after concluding (transactions involving stolen merchandise are kept longer). To avoid a truncation issue, we restricted attention to records originating within this 14-month period, thereby ensuring that no transaction contemporaneous to one in the data set could be omitted. To extend the available data window, the data were regathered at a later period and the two gatherings merged. Further filtering of spoiled records voided at origination but retained for auditing purposes as well as transactions with missing information resulted in 7517 observations which originated over a two year period from June 1, 2000, through May 31, 2002.

Table 1 disaggregates the resulting data by outcome and by item under agreement. The data are classified into four merchandise categories: appliances, electronics, furniture and other. ${ }^{5}$ Note that the first three categories are roughly equally represented with furniture the largest and appliances the smallest and, collectively, make up over $90 \%$ of items under agreement. Further, the data are classified by ultimate outcome into active, returned or charged off, i.e., still ongoing as of the data

\footnotetext{
${ }^{5}$ Appliances include, e.g., washers and dryers, refrigerators, and air conditioners. Electronics includes televisions and stereos. Furniture includes items for the living room and bedroom. Other includes jewelry and services such as a pager or cell phone access.
} 
Table 1

Data set disaggregated by agreement outcome and by items under agreement

\begin{tabular}{llcccc}
\hline Category & All & Appliances & Electronics & Furniture & Other \\
\hline All & $7,517(100 \%)$ & $2,057(27.37 \%)$ & $2,238(29.77 \%)$ & $2,667(35.48 \%)$ & $555(7.38 \%)$ \\
Active & $1,105(14.70 \%)$ & 342 & 271 & 407 & 85 \\
Returned & $4,673(62.17 \%)$ & 1,225 & 1,528 & 1,604 & 316 \\
$\quad$ Voluntary & $3,952(84.6 \%)$ & 1,011 & 1,304 & 1,357 & 280 \\
$\quad$ Involuntary & $721(15.4 \%)$ & 214 & 224 & 247 & 36 \\
Charged off & $1,739(23.13 \%)$ & 490 & 439 & 348 & 595 \\
$\quad$ Favorable & $1,513(87.00 \%)$ & 463 & 91 & 61 & 154 \\
$\quad$ Unfavorable & $226(13.00 \%)$ & 27 & & 47
\end{tabular}

The table disaggregates the data by number of observations; relative percentages are given in parentheses. Italized entries represent subtotals in the returned and charged off categories, respectively.

collection date; terminated with the return of the merchandise to the store; or, terminated without merchandise return, respectively. ${ }^{6}$ Inspection of this categorization reveals a customer base which has substantial issues making their required payments. Over $15 \%$ of returns are involuntary, i.e., occur following some type of collection problem and so more accurately may be denoted as "recovered." Additionally, 13\% of charge offs are unfavorable, i.e., represent merchandise neither recovered nor fully paid for-in our sample this is 226 transactions or $3.5 \%$ of the 6412 completed. Taken together, almost $15 \%$ of completed agreements terminate following some type of payment issue and, in nearly a quarter of these cases, the merchandise is written off as unrecoverable.

\subsection{Dependent variable}

The dependent variable used in this study is the proportion of rent paid. That is, actual rent paid relative to total rent where total rent implicitly assumes agreements go to term, i.e., total rent is rent per month times the maximum possible number of months. Percentage rent paid as the primary variable of analysis is attractive for several reasons. For instance, one common concern of consumer groups is the very high cost of RTO as an acquisition mechanism. In the extant literature, such cost calculations have been made assuming payment to term. If, in contrast to this, the average "purchaser" acquires the merchandise relatively early in the contract paying only a fraction of the total then the effective interest rate would be much less. Further, a complaint lodged against RTO is that they let the customer get close to ownership and then somehow manipulate the contract so that the item gets returned. These are both concerns that need to be addressed to make informed public policy. At the same time, they are empirical questions addressed by our dependent variable. We further believe this dependent variable contributes to our understanding of consumer behavior by allowing us to observe the impact of, e.g., payment structure, dollar size and chronologic contract length on proportionate rent paid which, in turn, offers evidence of the impact that the structure of the deal has on the outcome.

\footnotetext{
${ }^{6}$ A favorable charge off occurs when a customer acquires merchandise after making all scheduled payments or by exercising the early purchase option. Unfavorable is when the store gets neither all rent due nor the merchandise back writing the loss off to bad debt, damaged, skip, stolen or other. Likewise, an involuntary return is when the store recovers the merchandise after experiencing collection problems; voluntary is the item returned citing a short term need, cannot afford, exchange, service or other.
} 
Table 2

Sample median and mean of percentage rent paid

\begin{tabular}{|c|c|c|c|c|c|}
\hline Category & All & Appliances & Electronics & Furniture & Other \\
\hline Overall & $14.70(28.91)$ & $17.30(31.02)$ & $9.90(24.51)$ & $16.40(30.01)$ & $21.20(33.51)$ \\
\hline \multicolumn{6}{|l|}{ Contract outcome } \\
\hline Return & $6.90(13.05)$ & $7.70(13.40)$ & $5.10(11.26)$ & $7.80(13.55)$ & $9.00(17.86)$ \\
\hline Favorable charge off & $80.20(66.06)$ & $81.10(67.62)$ & $85.05(68.91)$ & $74.40(63.21)$ & $82.40(65.91)$ \\
\hline Unfavorable charge off & $20.10(26.55)$ & $19.00(27.48)$ & $14.40(24.46)$ & $26.40(29.33)$ & $20.90(26.44)$ \\
\hline \multicolumn{6}{|l|}{ Payment type } \\
\hline Weekly contracts & $6.00(19.77)$ & $6.40(20.84)$ & $4.60(16.22)$ & $6.80(20.57)$ & $11.70(28.30)$ \\
\hline Bi-weekly contracts & $30.80(41.16)$ & $32.50(41.69)$ & $27.00(37.17)$ & $31.10(42.54)$ & $44.25(47.33)$ \\
\hline Monthly contracts & $31.10(39.30)$ & $34.50(42.12)$ & $30.80(38.09)$ & $32.90(39.68)$ & $23.10(30.80)$ \\
\hline \multicolumn{6}{|l|}{ Payment history } \\
\hline On-time payer & $2.40(8.09)$ & $2.60(8.99)$ & $1.80(6.05)$ & $2.60(9.04)$ & $3.30(10.82)$ \\
\hline Late payer & $33.30(42.45)$ & $35.10(43.94)$ & $30.15(40.67)$ & $31.70(41.62)$ & $41.10(47.57)$ \\
\hline
\end{tabular}

For each category the median appears first with the mean next in parentheses. The calculations ignore censoring and therefore are biased downwards (see footnote 8). Statistics are provided for the proportion of rent paid both overall and disaggregated by contract outcome, payment schedule (frequency), and contract payment history; where on-time (late) is defined as none (at least half) of the payments made late.

Table 2 gives the median and mean values of this variable. ${ }^{7}$ Overall, the median (mean) rent paid is $14.7 \%$ (28.9\%) of the amount due under the RTO agreement reflecting, in part, many customers who either return or purchase early. This number clearly suggests that the contract is not functionally equivalent to installment credit for the average consumer. At the same time however, clearly some consumers are acquiring merchandise via RTO and so the previous fact alone does not settle the public policy question of whether there is a need to protect such "purchasers." Also of interest is the variation across the item subsets, with electronics having the smallest amount of rent paid and appliances the most.

The averages for the proportion of rent paid disaggregated by contract outcome, payment type, and payment history are also presented. With regard to contract outcome, we find that the overall median (mean) for favorable charge offs, i.e., purchases, is $80 \%(66 \%)$ - the average purchaser paying less than $100 \%$ reflects the exercise of the early purchase option - and for returns it is only $7 \%(13 \%)$. Note also that the median (mean) rent paid for unfavorable charge offs is just about $20 \%$ (27\%), further dramatizing the credit risk issue even ignoring the costs in time and effort of attempting collection. Even if due to their mark-up the store's loss from such behavior is relatively small, clearly such action is being subsidized by those customers using RTO to purchase merchandise.

Interestingly, the result that the mean rent paid is only $29 \%$ of total rent, with about $23.6 \%$ of the items actually purchased, is a complete reversal of the common perception that $60-70 \%$ of the goods are acquired under RTO contracts. ${ }^{8}$ There are a number of issues which partly reconcile

\footnotetext{
${ }^{7}$ The summary statistics are simple averages of the data set—including the active contracts which use the percent rent paid as of the observation date. This induces a downward bias in the table due to the limited observation period. That is, transactions that are very short are more likely to have had time to conclude while transactions running a relatively long period are more likely to be censored (still be active) and so the average will be too small. However, simply dropping the active contracts would exacerbate this bias. We note that the regression results are free of this bias as the methodology employed corrects for this in the estimated likelihood function.

${ }^{8}$ For example, FTC (2000) reports that $66.8 \%$ of customers intended to purchase the item being rented (their Table 5.1) and that, of the transactions completed at the time of survey, 64.3\% resulted in acquisition (their Table 5.2 shows, of the
} 
this difference but do not eliminate it. First, it should be noted that the sample mean is biased downward due to the $15 \%$ of observations that are active (censored) with customers continuing to make payments. Second, our data set is based on transactions while the extant literature focuses on customer surveys. Survey data suffers from misreporting, either simple memory errors or something more. ${ }^{9}$ Further, survey data may pick up customer intent which, of course, can diverge from the actual outcome. One can also argue there is a bias toward over-reporting purchases if that is perceived as a positive outcome while returns, particularly if involuntary, may be perceived negatively and under-reported. A related issue is consumer fraud; our sample shows a significant amount of items being charged off by stores as unrecoverable (stolen or damaged) and it is unlikely that such behavior would be reported in a telephone interview. Finally, there is the issue of merchandise exchanges. Another empirical regularity of our data set is a surprisingly high proportion of goods are returned in order to exchange them for a similar item. ${ }^{10}$ This represents an important consumer option to resolve uncertainty over a good's utility without having to suffer "buyer's remorse." It seems likely that on a survey this would be reported as a single transaction while, in our data set, it constitutes several. Taking another approach to reconciling these purchase rate differences, we calculate the proportion of customers who acquire at least one item. ${ }^{11}$ While this number should be closer to survey estimates, it does overstate the purchase rate in our sample, even so only $31.7 \%$ of customers are purchasers in this sense.

Our focus on proportion of rent paid allows us to make some indirect observations on the annual percentage rates (APRs) implicit in rent-to-own arrangements. Possibly the most striking feature of RTO is the very high cost of such financing. Existing literature reports that such contracts require total payments two to four times the retail price with APRs in excess of $100 \%$ and often much higher (Zikmund-Fisher \& Parker, 1999). Such benchmark calculations assume all required payments are made; however, our empirical evidence shows an average purchaser, by exercising the early purchase option, pays only a median (mean) rent of $80.20 \%(66.06 \%)$ thus mitigating the effective interest cost. Further, more than $60 \%$ of the items are returned and the data show substantial business risk due to items unrecoverable after relatively little has been paid, implying that actual returns are less than reported APRs. At the same time, while the true cost is not as high as extant estimates suggest, it is, like all subprime arrangements, dramatically higher than conventional financing arrangements.

Table 2 also disaggregates the proportion of rent paid variable by payment type and payment history. The results are striking. Contracts written with a weekly payment schedule conclude with a substantially lower percentage of rent paid as compared to those with non-weekly schedules; while the difference between bi-weekly and monthly is only marginal. Further, percentage rent paid is substantially smaller for customers who always make their payments on-time relative to those generally late.

An important issue regarding the analysis of rent payment is whether the rented merchandise is new or used. As contracts frequently end in return, a store will commonly be re-renting a given

total deals discussed, $48.5 \%$ resulted in purchase, $26.9 \%$ in return, $22.5 \%$ were still active, and $2.1 \%$ were Other/Do not Know/Refused).

${ }^{9}$ For example, FTC (2000) asked about transactions originated up to five years prior.

${ }^{10}$ For example, a customer renting a TV then returning it and, nearly simultaneously, renting a different TV, possibly repeating such an exchange several times.

11 This was calculated by determining that of the 3002 customers with an inactive contract, 952 had one conclude with purchase or payment to term. The presence of censored agreements biases this downward, but an upper bound can be estimated by assuming all active (censored) agreements will end in purchase, but even this loose bound only yields a $43.4 \%(=1425 / 3283)$ purchase rate. 


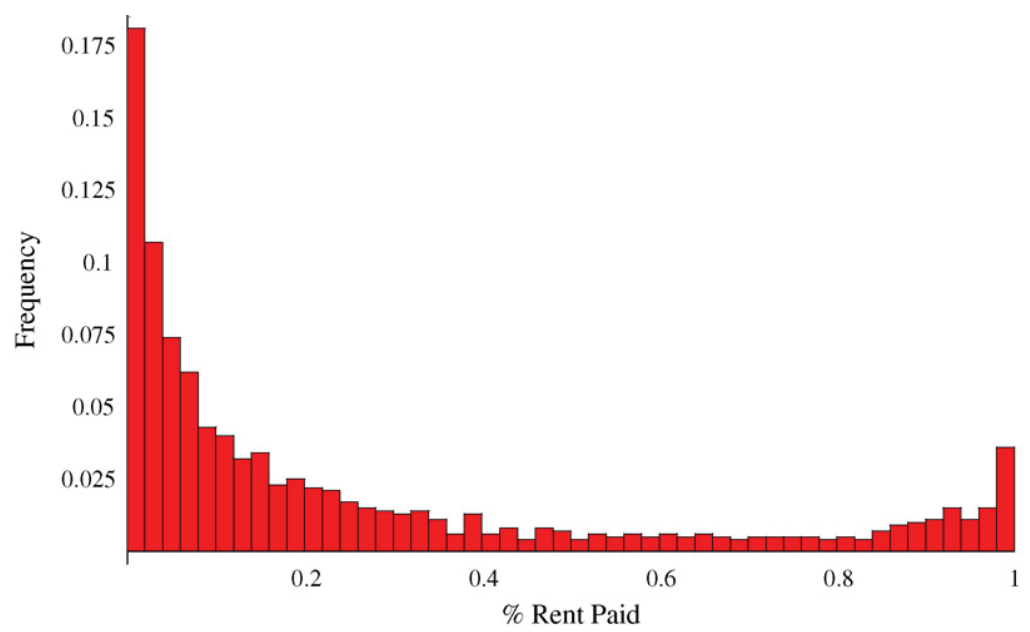

Fig. 1. The distribution of raw percentage rent paid is shown. The figure is a relative frequency histogram of the actual percentage rent paid for all 6412 completed transactions in the sample.

item. In our sample, $34.9 \%$ of the transactions involved unique merchandise; another $43.3 \%$ represented merchandise under two or three agreements; $94.6 \%$ involved merchandise rented five or fewer times and, at the other extreme, one item had been rented ten times. For each piece of merchandise, considering only the outcome of the last agreement, we found that the outcome-e.g., return, purchase, skip - was fairly invariant. Another issue is contractual fees. RTO agreements impose fees for, among other things, late payment, bounced checks, if the payment needs to be hand collected or if the agreement lapsed and needs to be reinstated. ${ }^{12}$ This paper only considers "pure" rent payments-fees as well as sales taxes are excluded from the study. We believe that this pure rent analysis does not pose any methodological bias since the sample appears fairly homogeneous with regard to contract terms-especially across the merchandise subgroups considered. One consequence of this, going back to Table 2 , is that we find chronically late customers end up paying more in actual rent.

Another interesting issue is the number of payments actually made by RTO customers. This depends somewhat on the agreement's payment structure. We find that for bi-weekly and monthly contracts, purchase (return) takes on average about a year (4 months). By contrast, weekly structured contracts resolve much faster with purchase (return) occurring in about one half (one third) of the time. While it is unsurprising that returns happen much faster - since if you knew you had only a short term need, you would rationally select a weekly payment schedule - it is interesting that when weekly payers purchase, via the early purchase option, they do so much quicker than do those with monthly payment schedules. We analyze this issue further with our formal model.

Fig. 1 presents a histogram showing the relative frequency of percentage rent paid, considering all 6412 transactions in our sample which have concluded. The figure shows that the distribution is right-skewed, starting high reflecting the short term rentals, then sharply declining, remaining flat reflecting the early purchase option, then rising somewhat at the end due to those paying to term.

\footnotetext{
$\overline{12}$ Further, some RTO contracts may entail a penalty for early return while others may require the consumer to purchase insurance on the rented merchandise. Unfortunately, a condition for obtaining the data was that the chain desired anonymity. Thus, we have no way to determine directly if there are requirements that customers rent a minimum number of weeks or take out insurance at this particular chain.
} 
Table 3

Sample mean and standard deviation of the independent variables

\begin{tabular}{llllll}
\hline Variable & All & Appliances & Electronics & Furniture & Other \\
\hline Age & $2.214(1.238)$ & $2.384(1.286)$ & $2.158(1.212)$ & $2.138(1.216)$ & $2.182(1.205)$ \\
Gender (1 if male) & $0.253(0.435)$ & $0.249(0.433)$ & $0.288(0.453)$ & $0.216(0.412)$ & $0.299(0.458)$ \\
Marital status $(1$ if married) & $0.252(0.434)$ & $0.275(0.447)$ & $0.247(0.431)$ & $0.238(0.426)$ & $0.256(0.437)$ \\
Employment $(1$ if $>6$ mn) & $0.471(0.499)$ & $0.465(0.499)$ & $0.468(0.499)$ & $0.474(0.499)$ & $0.495(0.500)$ \\
Income & $2.321(1.231)$ & $2.353(1.208)$ & $2.374(1.279)$ & $2.267(1.205)$ & $2.245(1.235)$ \\
Government aid $(1$ if aid) & $0.349(0.477)$ & $0.338(0.473)$ & $0.349(0.477)$ & $0.361(0.480)$ & $0.335(0.472)$ \\
Referral $(1$ if referred) & $0.157(0.364)$ & $0.161(0.368)$ & $0.161(0.367)$ & $0.146(0.353)$ & $0.177(0.382)$ \\
Bi-weekly payment & $0.258(0.438)$ & $0.266(0.442)$ & $0.239(0.426)$ & $0.270(0.444)$ & $0.245(0.431)$ \\
Monthly schedule & $0.185(0.389)$ & $0.217(0.413)$ & $0.151(0.358)$ & $0.183(0.387)$ & $0.220(0.414)$ \\
Maximum payable amount & $1.268(0.952)$ & $1.141(0.581)$ & $1.412(1.196)$ & $1.382(0.956)$ & $0.608(0.486)$ \\
Contract length & $1.262(0.370)$ & $1.276(0.372)$ & $1.280(0.385)$ & $1.266(0.334)$ & $1.119(0.426)$ \\
Proportion late & $0.368(0.312)$ & $0.392(0.312)$ & $0.333(0.314)$ & $0.383(0.310)$ & $0.347(0.301)$ \\
Median days late & $1.741(3.361)$ & $1.824(2.633)$ & $1.538(2.498)$ & $1.849(3.726)$ & $1.730(5.937)$ \\
Standard deviation late & $2.393(3.952)$ & $2.350(2.874)$ & $2.225(4.705)$ & $2.484(3.243)$ & $2.783(6.403)$ \\
Transactions to date & $2.961(2.987)$ & $2.685(2.991)$ & $3.002(3.291)$ & $3.083(2.615)$ & $3.231(3.282)$ \\
Repeat customer $(1$ if repeat) & $0.450(0.498)$ & $0.406(0.491)$ & $0.475(0.500)$ & $0.443(0.497)$ & $0.548(0.498)$ \\
\hline
\end{tabular}

The mean appears first with the standard deviation next in parentheses.

\subsection{Independent variables}

It is hypothesized that the value of the proportion of rent paid depends on the following list of customer- and transaction-specific variables; the mean values of these variables along with their standard deviations are presented in Table $3 .{ }^{13}$

- Age

- Gender

- Marital status

- Employment

- Income

- Government aid

- Referral

- Bi-weekly payment

- Monthly payment

- Maximum payable amount

- Contract length

- Proportion late

- Median days late

- Standard deviation late

- Transactions to date

- Repeat customer
Qualitative age variable; 1 for 18-25 years old, 2 for 26-30 years old, 3 for

31-40 years old, 4 for 41-55 years old, and 5 for 56+ years old

Dummy variable; 1 if male

Dummy variable; 1 if married

Dummy variable; 1 if employed for over 6 months

Qualitative income variable (in US\$ 1000s); 1 for $0-5,2$ for 5-10, 3 for 10-15, 4 for $15-20,5$ for 20-25, and 6 for more than 25

Dummy variable; 1 if the customer receives government aid in the form of

TANF, Social Security, or welfare

Dummy variable; 1 if the customer is a referral

Dummy variable; 1 for bi-weekly payment schedule

Dummy variable; 1 for monthly payment schedule

Periodic payment amount multiplied by the total number of payments, assuming all payments are made (in US\$ 1000s)

Maximum duration (in years) of agreement, if full term

Proportion of payments of each agreement that are made late

Median number of days payments are late

Standard deviation of the number of days payments are late

Number of transactions originated no later than the current transaction

Dummy variable; 1 if the customer has several, distinct transactions

With respect to customer-specific factors, a number of demographic variables were considered. Age, $40.1 \%$ of the sample was $18-25$ years old, $61.0 \%$ was 30 or under, $83.0 \%$ was under 40

\footnotetext{
${ }^{13}$ Given the possibly related variables, we investigated multicollinarity and our exploratory analysis suggested that it was not an issue.
} 
and $94.5 \%$ was 55 or less. Gender, females are greatly over-represented in the sample at $74.7 \%$. Martial status, 25.2\% reported being married while divorced, singled and widowed were 27.1, 46.6 and $1.1 \%$, respectively. Employment, $47.1 \%$ report having been employed more than 6 months. Income, the mean income was slightly over US\$10,000 with $97.4 \%$ below US\$25,000. Government aid, 34.9\% reported receiving aid in the form of either TANF-temporary assistance for needy families (71\% of aid recipients), Social Security (26\%), or welfare (3\%). We note that these demographics are gathered at the store level at contract origination; however, they are generally consistent with existing literature (e.g., FTC, 2000) but are not directly comparable being transaction- and not customer-based. Further, concern about possible bias introduced by misreporting is mitigated by their relatively minor explanatory role, as is discussed in Section 4 . We are also able to explicitly check for a reference group effect as customers were asked how they heard of the store; one response was referral, either directly or because a friend or relative was also a customer. This is captured by a dummy variable whose mean reveals that $15.7 \%$ of transactions were so generated.

The transaction-specific factors are divided into those concerning contract structure, usage and payment history, respectively. Three contract structure variables were considered. First is payment type; the RTO agreement can be structured to require weekly, bi-weekly or monthly payments. This ability to tailor payments to income stream is an interesting consumer option as the customer has free choice from the menu of payment amounts and corresponding due dates. We capture this effect by constructing dummy variables for bi-weekly and monthly payment schedules. Nearly $56 \%$ of agreements are on a weekly schedule with bi-weekly and monthly schedules totaling 26 and $18 \%$, respectively. Considering the three merchandise subgroups, we note that appliances are least likely to be on a weekly schedule, electronics the most. The second variable is maximum payable amount, the undiscounted sum of all scheduled payments over the life of the agreement. The sample mean is US\$ 1268 with average electronics and furniture contracts running about US\$ 1400 and appliance contracts about US\$ 1100 . The third variable is contract length given that the agreement is not terminated early. The mean length, nearly constant across groups, is just over 15 months. Notice these three structure variables, taken together, completely capture the financial details of acquiring merchandise by paying to term with a RTO agreement-i.e., how much, how long, and the frequency of payments.

The two contract usage variables focus on repeat business. The first is transactions to date, i.e., the number of transactions begun no later than the current transaction by that particular customer. The sample mean is 2.96 transactions to date, with the average customer doing 2.29 transactions (dividing records by unique customers) in our sample. Clearly, having multiple transactions is common with RTO customers; however, the presence of multiple records does not necessarily imply a repeat customer. To further explore this, a dummy variable is used with a customer counted as a repeat only if his or her current transaction history contains an agreement not associated with any other transaction. Thus, a customer is not counted as a repeat if he or she has only one agreement in the data set or if the multiple agreements all have the same origination date - e.g., several items rented at one time but placed on separate agreements - or if the agreements ran sequentially, with one starting the same date the prior one ended-e.g., a customer renting an item then returning it in exchange for another. Looking at the sample mean, $45 \%$ of customers are repeat in the above sense.

Contract payment history is captured with three variables. The first, proportion late, is simply the number of late payments divided by the total number of payments made. The sample mean is $36.8 \%$, i.e., almost two of every five payments are late, a fairly striking result. Further, while this proportion is similar for the three subgroups, we note that it is highest for appliances and 
lowest for electronics, echoing the differences in payment type among groups. Second, we consider the median days that individual payments are late. Note that, for a given transaction, this variable is zero unless at least half the payments are late. It is a measure of lateness for the $44 \%$ of transactions for which the majority of payments are not on-time, capturing extreme delays in making payments. The final variable is the standard deviation of the number of days that payments are late for each transaction's payment history. Thus, if a customer always paid on-time or was always, say, a day late, the standard deviation would be zero while it increases with payment variability. The idea is predictability of payments should proxy for a consumer's financial uncertainty. Together, these three variables capture if payments are late, how late, and the predictability of lateness, respectively. ${ }^{14}$

\section{Methodology}

The dependent variable in this study is the proportion of rent paid. As seen in Table 1, the exact value of this variable is available for $85.3 \%$ of the contracts. For such contracts, the transaction has concluded either as a charge off or as a return (these outcomes are defined in footnote 7 and detailed in Table 1). In the remaining $14.7 \%$ of the cases, the contract is still active at the end of the data acquisition period and represents a right-censored observation as the customer is still paying rent.

Let $y_{i}^{*}$ be a latent variable representing the proportion of rent paid in a RTO contract where $y_{i}^{*}$ is not observable for some $i=1,2, \ldots, N$. The observed variable, $y_{i}$, denotes the proportion of rent paid at the end of the data acquisition period. For completed contracts $y_{i}^{*}=y_{i}$ and for active contracts $y_{i}^{*} \geq y_{i}$ implying that $y_{i}^{*}$ is right censored at $y_{i}$. As is customary in Tobit-type censored models, we began our analysis under the assumption of homoscedasticity and normality. For a randomly drawn contract, let

$$
y_{i}^{*}=\beta^{\prime} x_{i}+\varepsilon_{i} \quad \text { where } \varepsilon_{i} \mid x_{i} \sim \operatorname{Normal}\left(0, \sigma^{2}\right)
$$

Let $C_{i}$ be an indicator variable that equals 1 if the contract is completed and 0 when it is censored. The log-likelihood for the censored regression models is

$$
L=C_{i} \sum_{i=1}^{N}\left[-\frac{1}{2} \ln \left(2 \pi \sigma^{2}\right)+\left(\frac{y_{i}-\beta^{\prime} x_{i}}{\sigma}\right)^{2}\right]+\left(1-C_{i}\right) \sum_{i=1}^{N} \ln \left[1-\Phi\left(\frac{y_{i}-\beta^{\prime} x_{i}}{\sigma}\right)\right]
$$

This likelihood function is maximized in the usual way to obtain the parameters estimates.

Censored models are known to be especially sensitive to the assumptions of normality and heteroscedasticity implied by (1) above. The estimates will generally be inconsistent if the errors are heteroscedastic or non-symmetric (see the special issue on this topic edited by Blundell, 1987). These assumptions are usually tested using the Lagrange Multiplier or the conditional moment restriction framework (see Chesher \& Irish, 1987, and Pagan \& Vella, 1989). ${ }^{15}$

We implement the above two specification tests, which overwhelmingly reject the assumption of homoscedasticity and normality at the $1 \%$ level. The histogram presented in Fig. 1 helps

\footnotetext{
14 The payment history variables are not strictly exogenous; however, given our transactional data, their inclusion allows us to document interesting relationships between payment history and contract usage.

${ }^{15}$ It is worth noting that tests based on the BHHH estimator are known to reject more often than the chosen level of significance, especially when the data are censored (see Jaggia, 1997).
} 
explain why the normal model may be inappropriate as the distribution of the percentage rent paid is clearly positively skewed. We employ the log-normal distribution as a more suitable parametric alternative. ${ }^{16}$ The model is attractive as it explicitly deals with the positive nature of the proportion of rent paid variable. Further, since the variance of a log-normally distributed variable is proportional to the square of its mean, it implicitly includes a particular kind of heteroscedasticity (see Amemiya, 1973). This distribution is also flexible in that it accommodates a variety of positively skewed shapes while still specializing to a symmetric distribution.

The distribution of $y^{*}$ is $\log$-normally distributed when $\ln \left(y^{*}\right)$ has a normal distribution with mean $\beta x_{i}$ and variance $\sigma^{2}$. The log-likelihood function of a log-normal model with censored observations is given by:

$$
\begin{aligned}
L= & \left.C_{i}{ }_{i=1}^{N}-\frac{1}{2}\left(\ln \left(2 \pi \sigma^{2} y^{2}\right)+\frac{\ln \left(y_{i}\right)-\beta x_{i}}{\sigma}\right)\right] \\
& +\left(1-C_{i}\right){ }_{i=1}^{n} \ln 1-\Phi \frac{\ln \left(y_{i}\right)-\beta x_{i}}{\sigma}
\end{aligned}
$$

The results of the log-normal model are presented in Table 4. We should bear in mind that the coefficients $\beta$ measure the marginal effect of the factor on the conditional median (or mean) in the normal regression model. For a log-normal model, the relevant conditional mean and median are:

$$
E\left(y_{i}^{*} \mid x_{i}\right)=\exp \quad \beta x_{i}+\frac{\sigma^{2}}{2} \quad \text { and } \quad \operatorname{Med}\left(y_{i}^{*} \mid x_{i}\right)=\exp \left(\beta x_{i}\right)
$$

The estimated marginal effect on the median and mean at the average factor values, for all transactions, are $0.14 \beta$ and $0.32 \beta$, respectively. The next section of the paper presents and analyzes the results derived from our lognormal model.

\section{Results}

We begin by focusing on overall, aggregated transactions, i.e., the first column in Table 4 . Throughout this section "significant" means significant at the $1 \%$ level unless otherwise noted. One picture that emerges, looking at customer-specific factors, is that it seems to be the "working poor" that are paying more rent. This is supported by the employment length variable being positive and significant while the income level variable is negative and significant. This is consistent with the notion that the longer an individual remains employed at a low income job the more likely that situation will persist and so the more valuable is RTO as a means to acquire merchandise. Further support comes from the variable for the consumer's age being positive and significant as it is reasonable to believe that the older one gets, still having low income, the fewer are the available alternatives. The gender and marital status variables are both insignificant, generally. Interestingly, whether or not the consumer receives government aid is negative and significant in

\footnotetext{
${ }^{16}$ We also estimated a semi-parametric, censored least absolute deviation (CLAD), model that provides consistent estimates for censored data even when the data are non-normal and heteroskedastic (see Melenberg \& Soest, 1996, for a good application). The corresponding results are qualitatively similar to those obtained from the log-normal model but are not included in the paper for the sake of brevity.
} 


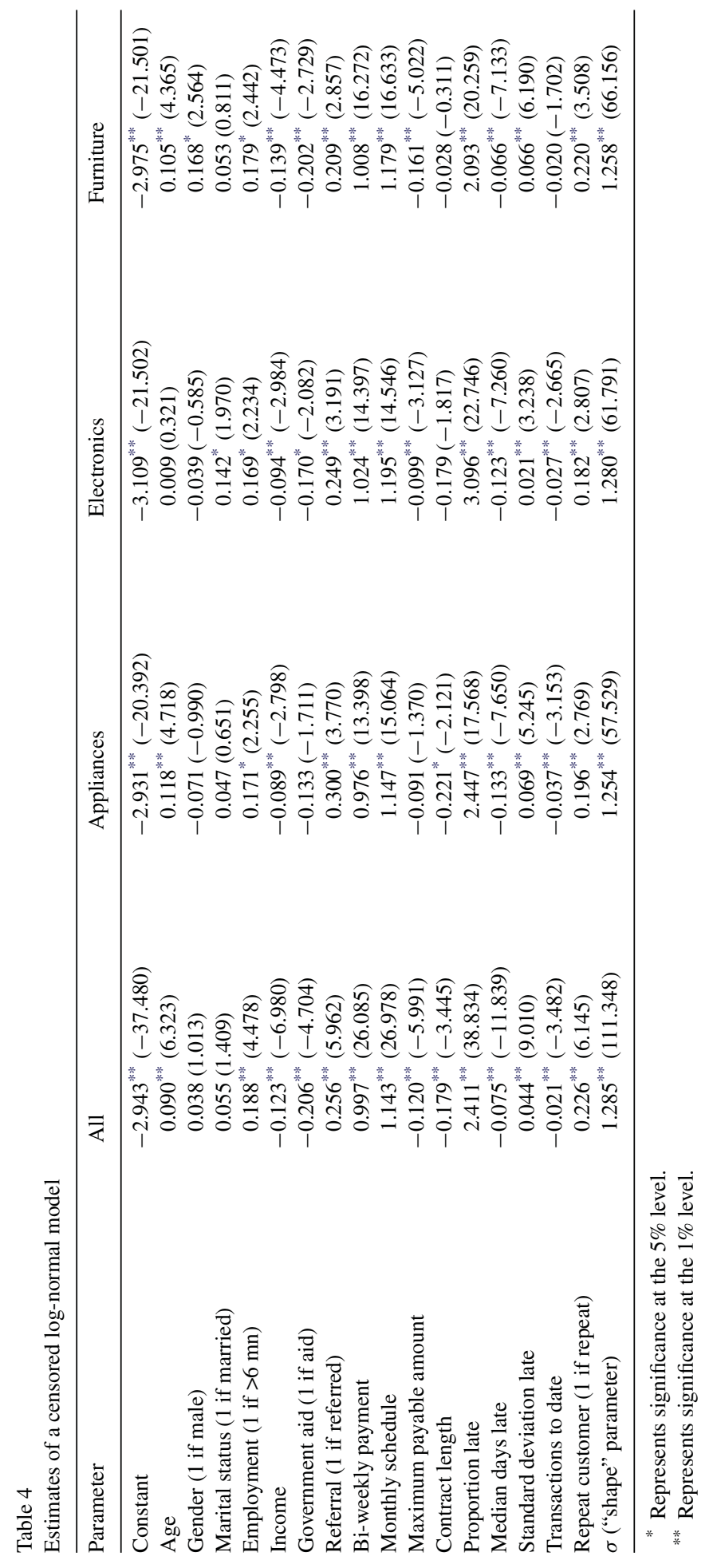


the log-normal model. This is somewhat suggestive that aid is picking up transitional periods in a consumer's life. The referral variable is positive and significant, suggesting some type of reference group effect, with consumers whose circle of contacts contains other RTO customers being more likely to use this arrangement as a means to acquire merchandise. These results are generally consistent with McKernan et al. (2003) which, using the FTC (2000) data set, contrasted likely renter from purchasers. They found that likely purchasers (and so those paying more rent) tended to have lower income, less education, more children and were more likely to be unemployed and to be separated.

Turning to transaction-specific variables, we first consider the three contract structure variables. First is payment type, i.e., whether a weekly, bi-weekly or monthly payment schedule was selected by the consumer at the beginning of the agreement. The bi-weekly and monthly dummy variables are both highly significant with the coefficient being somewhat higher for the monthly dummy. These results suggest that those selecting monthly agreements pay a higher proportion of total rent than those with bi-weekly agreements who, in turn, pay more than those with weekly agreements. One possible explanation is that the payment schedule is selected based on the consumer's expected income stream and other available resources. This would imply that a consumer needing a weekly schedule has a more marginal financial existence than does someone opting for monthly and consequently is more likely to end up terminating - or being terminated in - the relationship. Another explanation is that this captures pre-selection by customers based on their expectation for the outcome, either rental or purchase. That is, those expecting to rent would prefer a weekly arrangement for the greater flexibility offered while those expecting to purchase prefer monthly for the greater convenience.

One can also hypothesize a behavioral component. Perhaps the greater frequency of payments under a weekly arrangement, relative to non-weekly, prompts a closer examination of the benefits and costs which is more likely to result in the positive action of the consumer returning the merchandise. This finding may appear to be anomalous in standard economic theory which says that the financing method is important only insofar as the present value of payments is minimized. However, our results suggest that the consumption process is partially explained by the way the purchase is financed. This is consistent with the general behavioral argument of mental accounting (see Thaler, 1985). For instance, Prelec and Loewenstein (1998) argue that due to the interaction between the pleasures of consumption and the pain of paying, the decisions made by consumers may well depend on the way the purchase is financed. Regardless of underlying reason, the effect of the payment type variables clearly reveals some type of clientele effect at work.

The remaining two structure variables, maximum payment amount and contract length, address the question of how much and how long. Both variables are found to be negative and significant. Perhaps these variables are capturing the impact of the greater financial burden placed on the customer by longer and/or more expensive agreements. Alternatively, such items are being viewed by consumers as luxury goods intended only for short-term rental, e.g., a big screen TV for a Superbowl party.

Turning next to contract usage variables we focus on the impact of repeat business. A reasonable prior seems to be that, for a given customer, more transactions equate into a greater reliance on this financing method and so into more rent paid. However, we find that the transactions to date variable is negative and significant implying that the more deals a customer has already done the less rent will be paid on a new transaction. Although this finding may appear counter intuitive, it can be reconciled by noting that it is not uncommon for one transaction to be terminated and a new one created due to a service problem or a customer desire to do an exchange for similar merchandise. To address this, we considered a repeat customer dummy that equals one only if the customer's 
current transaction history contains a transaction unrelated to any other, i.e., involving different merchandise and/or disjoint intervals. Consequently, it captures whether the customer was truly a repeat customer and, as expected, it is found to be positive and significant. The results found for contract length and repeat customers are also consistent with the Zikmund-Fisher and Parker (1999) thesis, given their emphasis on the difficulty such consumers have saving/self-managing.

Three variables were considered to evaluate contract payment history. The first is the proportion of payments made late, i.e., total late payments to total payments made for a given transaction. One would expect this variable to negatively influence total rent paid, either because the customer gives up trying to make the payments or the store acts to reclaim the merchandise. We find that this variable is highly significant but, interestingly, positively affects rent paid. A reasonable explanation is that this variable proxies for the financial uncertainty in a customer's life, i.e., the more difficulty one has in paying his or her bills the less likely he or she is to have access to other methods of acquisition. Alternatively, it may reflect on the personality trait of a customer who is not particularly efficient in managing either time or finances. As a practical matter, given the general lateness of RTO customers, the longer a contract runs the greater the proportion of late payments on average, resulting in a positive relation between rent paid and proportion late. The second variable is the median days late which is non-zero only if at least half of the payments are late (true for some $44 \%$ of the sample). Thus, increasing values represent not only difficulty paying on-time but also significant delays in making those payments. This variable is highly significant across all groups, and, in line with the original intuition, negatively affects rent paid. Finally, the standard deviation of the days late variable is positive and significant overall, consistent with the notion that this proxies income shocks to the consumer, with greater variability associated with less certain finances and so a greater need to use rent-to-own as a means to acquire merchandise.

Reviewing the above results, an important observation can be made. Comparing the customerand transaction-specific variables, it seems that as interesting as who these customers are, more important is how the contracts are being used. Qualitatively, the transaction-specific variables have greater explanatory power over a given contractual outcome. A reasonable conclusion is that RTO customers, despite the demographic variation, are actually fairly homogeneous. That is, the defining factor is their membership in this group, which is determined primarily by economic factors. Given this, the variation observed can be traced to the duration of stay in such an economic situation which is better explained by contract usage.

To further highlight the results, Table 5 presents some simulations using the estimated parameters to show how, for a representative consumer, the proportion of rent paid varies with a change in one variable. These simulations are carried out using the estimates from the censored lognormal model for both median and mean. Notice that the means exceed the medians, reflecting the skewness of the data. For instance, the estimated median (mean) evaluated at the average for all factors is $14.11 \%$ (32.26\%). In general, the estimated values are consistent with the descriptive measures in Table 2. Perhaps the most striking result is that the median (mean) rent paid more than doubles as one goes from weekly to bi-weekly payment schedules then increases still more going from bi-weekly to monthly schedules. These results seem to indicate that the clientele effect is not only significant, it is also very strong in magnitude. Also interesting is the roughly $30 \%$ jump in rent paid by older customers, reflecting a nearly $40 \%$ jump in the Appliance and Furniture categories but virtually no change in Electronics, moving from the 18-25 years old group to the 41-55 group. This is quite consistent with the hypothesis that the older one gets still having low income, the fewer are the available alternatives, as it appears that RTO is being used more as an acquisition mechanism and more for household essentials by the older age group. Similar predictions with respect to income level, referred customer, and repeat customer are informative as well. 
Table 5

Estimated median (mean) percentage rent paid

\begin{tabular}{|c|c|c|c|c|}
\hline Variable & All & Appliances & Electronics & Furniture \\
\hline Average & $14.11(32.22)$ & $16.52(36.26)$ & $10.23(23.21)$ & $15.52(34.24)$ \\
\hline \multicolumn{5}{|l|}{ Payment type } \\
\hline Weekly & $8.83(20.15)$ & $9.93(21.79)$ & $6.69(15.18)$ & $9.53(21.02)$ \\
\hline Bi-weekly & $23.92(54.63)$ & $26.33(57.79)$ & $18.64(42.27)$ & $26.10(57.56)$ \\
\hline Monthly & $27.68(63.19)$ & $31.27(68.63)$ & $22.12(50.17)$ & $30.97(68.31)$ \\
\hline \multicolumn{5}{|l|}{ Age } \\
\hline $18-25$ years & $12.65(28.87)$ & $14.03(30.79)$ & $10.13(22.98)$ & $13.77(30.38)$ \\
\hline $41-55$ years & $16.58(37.85)$ & $19.99(43.88)$ & $10.40(23.58)$ & $18.88(41.64)$ \\
\hline \multicolumn{5}{|l|}{ Income level } \\
\hline Less than US\$ 5,000 & $16.60(37.90)$ & $18.63(40.90)$ & $11.64(26.40)$ & $18.50(40.81)$ \\
\hline More than US\$25,000 & $8.97(20.49)$ & $11.93(26.20)$ & $7.28(16.52)$ & $9.25(20.41)$ \\
\hline \multicolumn{5}{|l|}{ Referred customer } \\
\hline 0 & $13.56(30.95)$ & $15.74(34.55)$ & $9.83(22.30)$ & $15.06(33.21)$ \\
\hline 1 & $17.50(39.96)$ & $21.25(46.64)$ & $12.61(28.61)$ & $18.55(40.93)$ \\
\hline \multicolumn{5}{|l|}{ Repeat customer } \\
\hline 0 & $12.74(29.10)$ & $15.25(33.48)$ & $9.38(21.28)$ & $14.08(31.06)$ \\
\hline 1 & $15.98(36.48)$ & $18.56(40.74)$ & $11.26(25.54)$ & $17.55(38.70)$ \\
\hline
\end{tabular}

Censored log-normal model. The table is constructed using the indicated variable value together with the mean factor values of all other model variables. For each category, the estimated median appears first with the mean next in parentheses.

Table 6

Estimated median (mean) percentage rent paid

\begin{tabular}{lrrlllrr}
\hline$p$ & $d$ & $m$ & $\sigma$ & \multicolumn{1}{l}{ All } & Appliances & \multicolumn{1}{l}{ Electronics } & \multicolumn{1}{l}{ Furniture } \\
\hline 0.00 & - & 0 & 0 & $5.96(13.62)$ & $6.86(15.06)$ & $4.21(9.56)$ & $6.67(14.71)$ \\
& 7 & 0 & 3.43 & $18.17(41.49)$ & $23.11(50.72)$ & $15.62(35.42)$ & $19.32(42.63)$ \\
0.40 & 14 & 0 & 6.86 & $21.11(48.19)$ & $29.24(64.17)$ & $16.77(38.05)$ & $24.23(53.45)$ \\
& 7 & 7 & 2.80 & $27.46(62.69)$ & $23.24(51.01)$ & $22.52(51.09)$ & $26.99(59.53)$ \\
0.80 & 14 & 14 & 5.60 & $18.38(41.96)$ & $11.11(24.39)$ & $10.11(22.94)$ & $20.46(45.13)$ \\
\hline
\end{tabular}

Censored log-normal model. In the table $p, m$ and $\sigma$ represent proportion, median and standard deviation late, respectively. We assume a binary distribution for payment timing, either 0 or $d$ days late, with $d=7$ and 14 . Note, $m=d(0)$ if $p>(<) 0.5$; further, $\sigma=d \sqrt{p(1-p)}$. For each category, the estimated median appears first with the mean next in parentheses.

Table 6 presents simulations with respect to the three payment history variables: proportion, median days, and standard deviation late. To provide more intuition into their relation, we induce a mapping into the days a given payment is late. We assume payments are made in a binary fashion, either on-time (zero days late) or some constant number of days late, $d$; then, given the proportion of late payments, this gives us a simple relation between a payment's number of days late and both the median and standard deviation late variables. ${ }^{17}$ Three different late proportions

\footnotetext{
${ }^{17}$ Letting $p, m$ and $\sigma$ represent proportion, median and standard deviation late, respectively, we have $m=d(0)$ if $p>(<) 0.5$ and $\sigma=\sqrt{p(d-p d)^{2}+(1-p)(0-p d)^{2}}=d \sqrt{p(1-p)}$. Note this last relation implies a right-skewed distribution with mean less than standard deviation, $\forall d>0$ and $p \in(0,0.5)$; this is consistent with the observed sample moments with the average and standard deviation of mean days late being 2.313 and 3.785 days, respectively.
} 
are considered. For the first, always on-time, the other two variables are zero and the estimated median (mean) rent paid is below 7\% (16\%) for all subgroups; perhaps illustrating that those organized enough with their finances to pay on-time are more likely to be just renting. Second, when $40 \%$ of payments are late, the median days late is zero and so only proportion and standard deviation affect the result. Consumers pay more rent than the first case, especially as payments go from one to two weeks late. Finally, when $80 \%$ of payments are late, the median late effect dominates the other two variables. Although, for payments one week late, rent paid increases as the proportion late goes from 40 to $80 \%$, the increase in days late from one to two weeks reduces rent paid. It is worth mentioning that the 90th percentile for median days late is only 6 days so these results are illustrative rather than predictive. Assuming a correlation between late payment behavior and consumer financial uncertainty, Table 6 illustrates how greater uncertainty translates into greater reliance on rent-to-own as a financing method and is consistent with the sample characteristics presented in Table 2. It is also worth noting that this illustration agrees with the more psychological results found by Zikmund-Fisher and Parker (1999), where preference for RTO seemed to reflect a response to financial uncertainty.

To gain additional insights, the data set was partitioned into merchandise categories: appliances, electronics, and furniture; this breakdown is reported in Table 1. Comparison of the model estimates on these subgroups (the last three columns in Table 4) suggest that the results are broadly similar, although different in magnitude. Further we note some intriguing differences. For instance, relative to other renters, those contracting for furniture tend to be younger and have lower income, suggesting some type of life cycle effect. Also interesting is the gender behavioral difference suggesting that men are least likely to instigate a furniture rental but when they do, they pay a higher proportion of rent. Electronics is alone in being influenced by martial status; specifically, those married pay more rent. Finally, the appliance category is unique among the subgroups in not being influenced by the maximum amount due and by the presence of government aid — both factors elsewhere reducing rent paid.

The above analysis makes no explicit allowance for the difference between the behavior of renters and purchasers. It is however possible that there is some type of preselection distorting the results. That is, we may have "renters" and "purchasers" who behave fundamentally different - this would agree with Fig. 1 where perhaps the early peak is due to renters and the smaller peak at the end from purchasers. To allow for the psychology underlying consumer behavior to differ, the percentage of rent paid variable is analyzed for renters (purchasers) by excluding purchasers (renters) from the sample. ${ }^{18}$ Table 7 provides the model estimates. The model predicts, evaluating at mean factor values, an overall median percentage rent paid of $11.02 \%(75.62 \%)$ for returns (purchases) — consistent with the sample values in Table 2.

It is interesting how qualitatively similar the results are in terms of both covariate signs and levels of significance. This robustness provides a check for our general methodological approach. However, the partitioning highlights the difference in the magnitude of the estimated parameters. For instance, as we move from a weekly to a monthly contract, the median percentage rent paid increases from 7.49 to $20.85 \%$ for a renter but only from 57.89 to $82.12 \%$ for a purchaser. This shows that weekly contracts are not only associated with a lower purchase probability $-37 \%(65 \%)$ of the completed purchases (rentals) are on weekly schedules - they also terminate quicker. As mentioned earlier, we believe it is the frequency of reminders in a weekly schedule that makes

\footnotetext{
${ }^{18}$ Such a partitioning introduces a possible sample selection bias, however, it affords additional insights into consumer behavior. We thank an anonymous referee for the suggestion.
} 
Table 7

Estimates of a censored log-normal model for return and purchase

\begin{tabular}{lcc}
\hline Parameter & Return & Purchase \\
\hline Constant & $-3.209^{* *}(-36.769)$ & $-2.040^{* *}(-15.664)$ \\
Age & $0.056^{* *}(3.514)$ & $0.062^{* *}(2.724)$ \\
Gender (1 if male) & $0.064(1.550)$ & $0.222^{* *}(3.532)$ \\
Marital status (1 if married) & $0.063(1.446)$ & $-0.055(-0.897)$ \\
Employment (1 if $>6$ mn) & $0.156^{* *}(3.407)$ & $0.155^{* *}(2.222)$ \\
Income & $-0.108^{* *}(-5.522)$ & $-0.072^{* *}(-2.598)$ \\
Government aid (1 if aid) & $-0.153^{* *}(-3.195)$ & $-0.336^{* *}(-4.606)$ \\
Referral (1 if referred) & $0.195^{* *}(4.082)$ & $0.236^{* *}(3.606)$ \\
Bi-weekly payment & $0.945^{* *}(22.224)$ & $0.526^{* *}(8.561)$ \\
Monthly schedule & $1.024^{* *}(20.387)$ & $0.355^{* *}(5.624)$ \\
Maximum payable amount & $-0.098^{* *}(-4.735)$ & $0.212^{* *}(4.640)$ \\
Contract length & $-0.117^{*}(-2.015)$ & $0.463^{* *}(5.390)$ \\
Proportion late & $1.997^{* *}(26.640)$ & $1.168^{* *}(11.399)$ \\
Median days late & $-0.114^{* *}(-14.231)$ & $-0.042^{* *}(-4.888)$ \\
Standard deviation late & $0.174^{* *}(17.080)$ & $0.045^{* *}(4.581)$ \\
Transactions to date & $-0.011(-1.760)$ & $0.004(0.343)$ \\
Repeat customer (1 if repeat) & $0.200^{* *}(4.987)$ & $0.175^{* *}(2.810)$ \\
$\sigma$ ("shape" parameter) & $1.240^{* *}(93.676)$ & $1.111^{* *}(55.631)$ \\
\hline Renters (purchasers) are analyzed & \\
\hline
\end{tabular}

Renters (purchasers) are analyzed by excluding transactions that concluded with a purchase (return) from the sample.

* Represents significance at the $5 \%$ level.

** Represents significance at the $1 \%$ level.

the early purchase option attractive in that the earlier you buy, the less you pay in total. So again, one sees those under a weekly schedule coming to a conclusion quicker.

The separate analysis also sheds light on some important differences in response to some factors by renters and purchasers. For instance, the contract structure variables - maximum payable amount and contract length - are highly significant for both models. However, for renters they exert a negative influence on the percentage rent paid whereas for purchasers it is positive. For illustration, consider two contract structures: US\$ 500 maximum amount on a 6-month contract, and US\$ 1000 maximum amount on a 12-month contract. The percentage rent paid for returns (purchases) is estimated as $13.20 \%(47.55 \%)$ for the former and $11.83 \%(66.79 \%)$ for the latter. As the latter contract would be associated with the underlying merchandise being less affordable, it is not surprising that there would be more time required in contract and so a greater percentage rent paid in the case of purchasers. Similarly, for a given short-term rental need, as either of those structure variables increase, percentage rent paid would naturally decline.

\section{Conclusions}

This paper examined rent-to-own contracts. It utilized data comprised of some 7500 actual transactions in contrast to existing literature which has relied on interview or survey data. One important policy question involves whether, in practice, an RTO contract is used as a rental/lease agreement with built-in purchase option, or as something more akin to an installment credit agreement. We find that RTO is more like a lease as $72.88 \%$ of completed agreements resulted in the return of the item to the store. Further, we find that the median (mean) percentage rent paid is $14.70 \%(28.91 \%)$. The data also highlight the presence of significant business risk. We find that unfavorable charge offs (where the store writes off the merchandise as unrecoverable) represent 
almost $13 \%$ of total charge offs and in such situations the median (mean) rent paid is about $20 \%(27 \%)$. A significant attraction of RTO is immediate access to merchandise without a credit check; however, our data shows that this involves significant cross-subsidization of customers, which helps explain the high APRs reported in the literature.

To more formally examine the rent a customer pays, we employed a Tobit type log-normal model for censored data. The variable of interest was the proportion of rent paid relative to that due if the contract went to term. We found that transaction-specific variables have greater explanatory power on the amount of rent that a customer pays than customer-specific ones. It appeared that RTO consumers are defined more by their economic circumstances than by demographics; the most striking implication being that consumers end up paying more rent when they are disorganized - either by nature or circumstance, as evidenced by their late payment behavior, or when the contract specifies payments either bi-weekly or monthly, as opposed to weekly. RTO customers are the "working poor," frequently viewed as unsophisticated but clearly with few financial options. Rent-to-own is possibly a valuable option given a choice not between cash or charge but rather between layaway or deferring consumption. We found that in general the percentage of rent paid is fairly low, due in part to the large proportion of returns. While some of these returns represent "failed purchases," it seems plausible that associated with financial uncertainty is uncertainty over aspects of personal life and so a sizable number of these returns do reflect short term needs.

\section{Acknowledgements}

The authors wish to acknowledge the helpful comments of Gregory Elliehausen, George Kanatas, Satish Thosar, Pravin Trivedi and two anonymous referees. Any errors are ours alone.

\section{References}

Amemiya, T. (1973). Regression analysis when the variance of the dependent variable is proportional to the square of its expectation. Journal of American Statistical Association, 68, 928-934.

Anderson, M. H., \& Jackson, R. (2001). A reconsideration of rent-to-own. Journal of Consumer Affairs, 35, 295-307.

Andreasen, A. R. (1993). Revisiting the disadvantaged: old lessons and new problems. Journal of Public Policy and Marketing, 12(2), 270-275.

APRO-Association of Progressive Rental Organizations. (2001). Industry revenue exceeds $\$ 5$ billion. View (APRO Newsletter), September 4.

Blundell, R. (Ed.). (1987). Specification testing in limited and discrete dependent variable models. Journal of Econometrics, 34 [Annals].

Chesher, A., \& Irish, M. (1987). Residual analysis in the grouped and censored normal linear model. Journal of Econometrics, 34, 33-61.

Federal Trade Commission (2000). Survey of rent-to-own customers. Bureau of Economics Staff Report. Washington DC.

Freedman, A. M. (1993). Peddling dreams: a marketing giant uses its sales prowess to profit on poverty. The Wall Street Journal, September 22, pp. A1, A10.

Hill, R. P., Ramp, D. L., \& Silver, L. (1998). The rent-to-own industry and pricing disclosure tactics. Journal of Public Policy and Marketing, 17, 3-10.

Jaggia, S. (1997). Alternative forms of the score test for heterogeneity in a censored exponential model. The Review of Economics and Statistics, 79(2), 340-343.

Lacko, J. M., McKernan, S.-M., \& Hastak, M. (2002). Customer experience with rent-to-own transactions. Journal of Public Policy and Marketing, 21, 126-138.

McKernan, S.-M., Lacko, J. M., \& Hastak, M. (2003). Empirical Evidence on the determinants of rent-to-own use and purchase behavior. Economic Development Quarterly, 17(1), 33-52.

Melenberg, B., \& Van Soest, A. (1996). Parametric and semi-parametric modeling of vacation expenditures. Journal of Applied Econometrics, 11(1), 59-76. 
Pagan, A., \& Vella, F. (1989). Diagnostic tests for models based on individual data: a survey. Journal of Applied Econometrics, 4(Supplement), S29-S59.

Prelec, D., \& Loewenstein, G. (1998). The red and the black: mental accounting of savings and debt. Marketing Science, 17(1), 4-24.

Swagler, R. M., Burton, J., \& Lewis, J. K. (1995). The alternative financial sector: an overview. Advancing the Consumer Interest, 7(2), 7-12.

Swagler, R. M., \& Wheeler, P. (1989). Rental-purchase agreements: a preliminary investigation of consumer attitudes and behaviors. Journal of Consumer Affairs, 23, 145-160.

Thaler, R. (1985). Mental accounting and consumer choice. Marketing Science, 4, 199-214.

Walden, M. L. (1990). The economics of rent-to-own contracts. Journal of Consumer Affairs, 24, 326-337.

Zikmund-Fisher, B. J., \& Parker, A. M. (1999). Demand for rent-to-own contracts: a behavioral economic explanation. Journal of Economic Behavior and Organization, 38, 199-216. 